\title{
MODELING CRYPTOSPORIDIUM PARVUM OOCYST INACTIVATION AND BROMATE FORMATION IN A FULL-SCALE OZONE CONTACTOR
}

\author{
George Tang ${ }^{1}$, Kwabena Adu-Sarkodie ${ }^{2}$, Dooil Kim ${ }^{3}$, Jae-Hong Kim ${ }^{3}$, Susan Teefy ${ }^{4}$, Hiba M. \\ Shukairy ${ }^{5}$, and Benito J. Mariñas ${ }^{1 *}$ \\ ${ }^{1}$ Department of Civil and Environmental Engineering, University of Illinois at Urbana- \\ Champaign, Urbana, Illinois 61801 \\ ${ }^{2}$ Damon S Williams Associates, Phoenix, Arizona 85016 \\ ${ }^{3}$ School of Civil and Environmental Engineering, Georgia Institute of Technology, Atlanta, \\ Georgia 30332 \\ ${ }^{4}$ Water Quality \& Treatment Solutions, Inc., Castro Valley, California 94546 \\ ${ }^{5}$ US Environmental Protection Agency, Technical Support Center, Cincinnati, Ohio 45268
}

\section{SUPPLEMENTAL INFORMATION}

\section{Full-scale Contactor Hydrodynamics}

The results obtained for the tracer test performed at the target water flow rate of 7 MGD are shown in Figure S-1. The data was analyzed to obtain the mean residence times through the effluent sampling ports of chamber sections $1 \mathrm{~A}$ and 5B. The resulting values were $\bar{t}=3.7$ and $24.2 \mathrm{~min}$, respectively, corresponding to an actual water flow rate of 7.45 MGD, a value within 7 percent of the target flow rate of 7 MGD. The tracer curves at the effluent of chamber sections $1 \mathrm{~A}$ and $5 \mathrm{~B}$ were then predicted using dispersion numbers calculated with the expressions $\left(d_{1 \mathrm{~A}} / d_{1 \mathrm{~A}, 0}\right)=\left(d_{1 \mathrm{~B}} / d_{1 \mathrm{~B}, 0}\right)=\ldots=\left(d_{5 \mathrm{~B}} / d_{5 \mathrm{~B}, 0}\right)=\left(Q_{L, 0} / Q_{L}\right)$, in which the subscript "0" indicate the reference flow rate of 13.2 MGD. Greater discrepancies were observed between experimental and predicted curves depicted in Figure S-1 compared to those for the test shown in Figure 6 of the manuscript. This might have been due to errors incurred by applying the model assumptions, possibly compounded with experimental errors such as changes in water flow rate during the

\footnotetext{
*Corresponding author phone: (217) 333-6961; fax: (217) 333-6968; e-mail: marinas@uiuc.edu.
} 
performance of the test. Despite these discrepancies the ADR model with its simplifying assumptions was deemed adequate to represent the hydrodynamics of the ACWD contactor.

Full-Scale Model Application

The results for Tests 4-6 are presented in Figure S-2. Although similar to the observation for Tests 2 and 3, the bromate concentration did not drop below the MCL of $10 \mu \mathrm{g} / \mathrm{L}$ for any of these three additional tests, the bromate formation was lower at lower dispersion. 


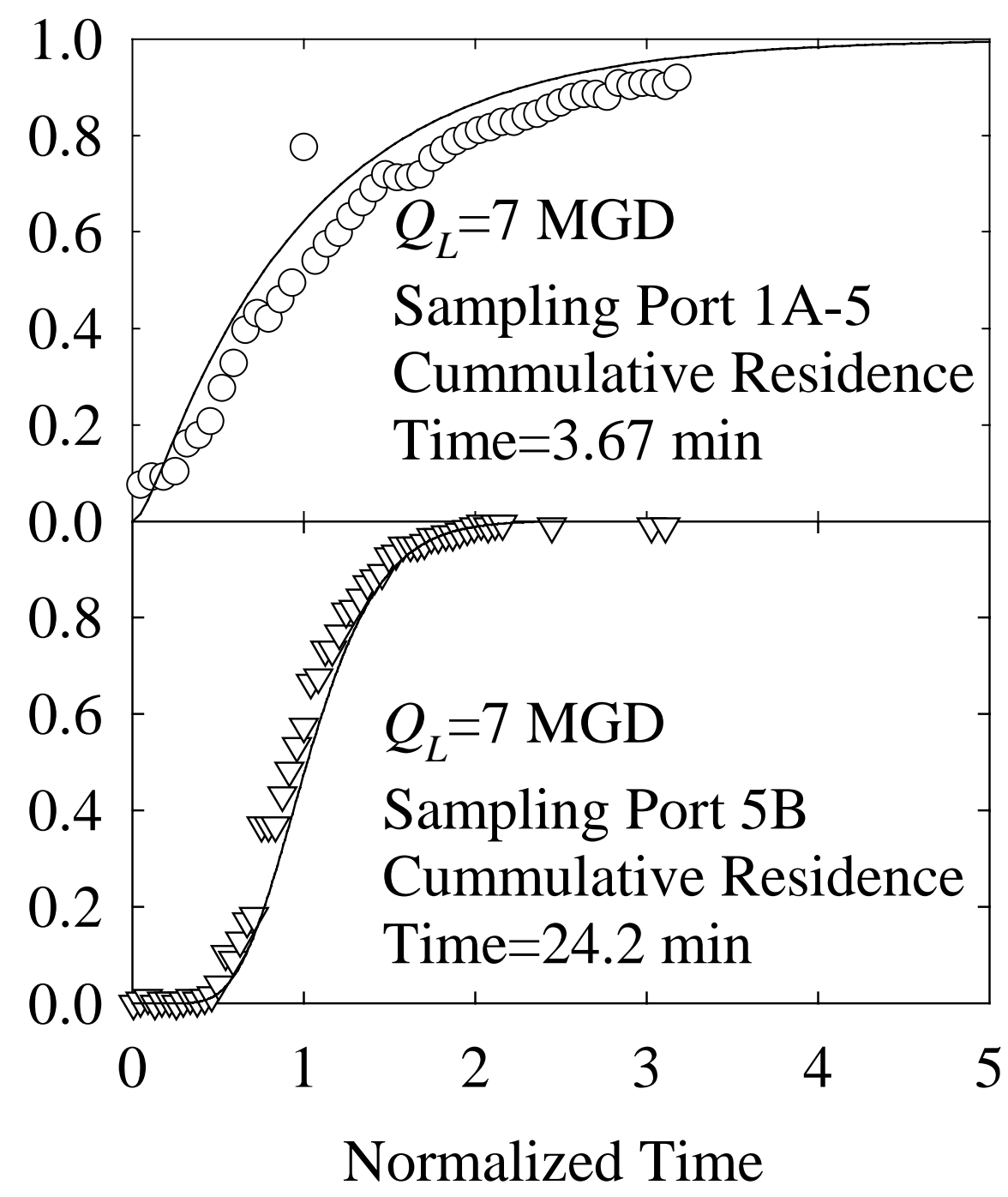

Figure S-1. Tracer test performed with the ACWD ozone contactor at a target water flow rate of 7 MGD. 


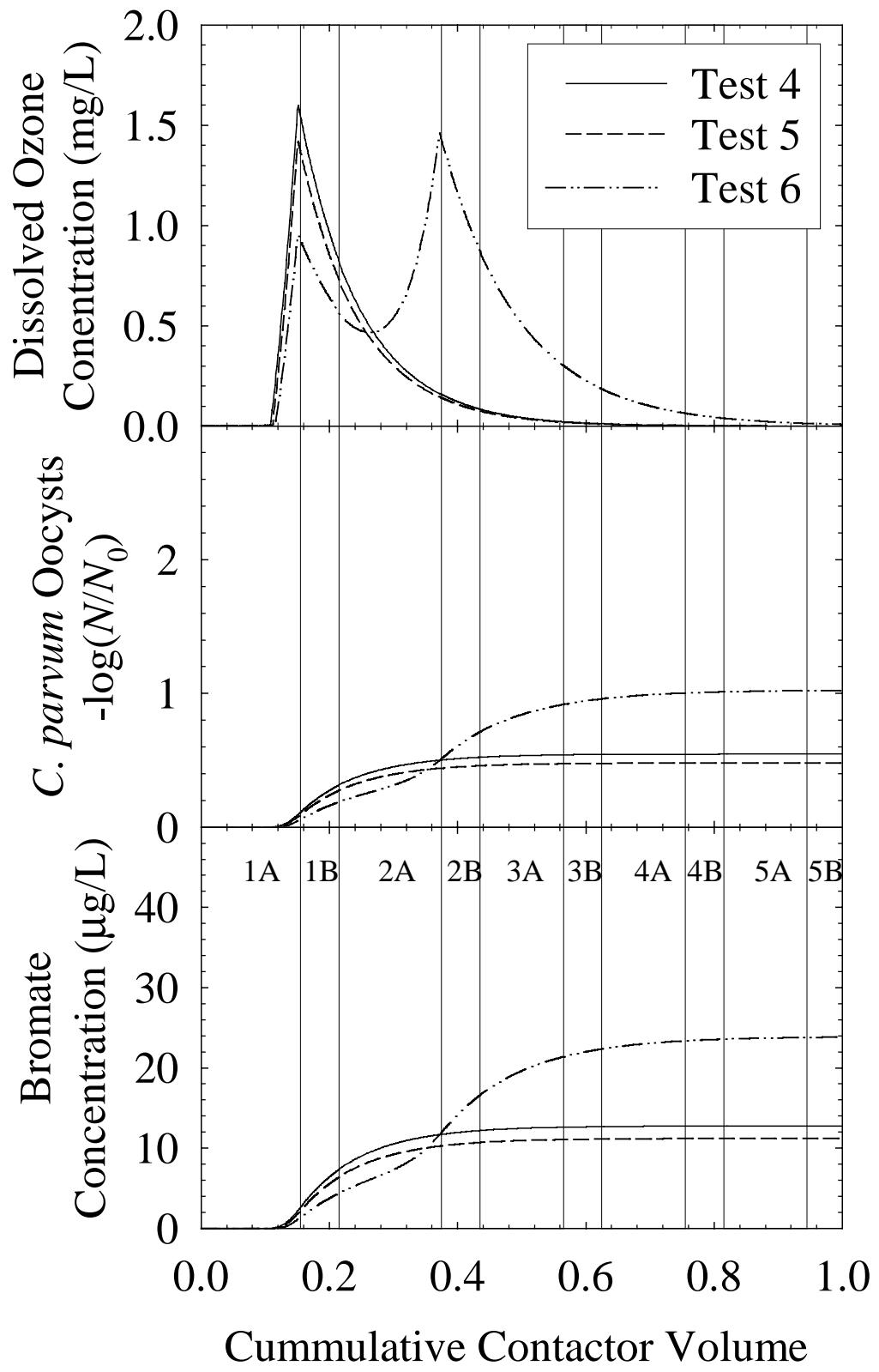

Figure S-2. Predicted dissolved ozone concentration, log inactivation and bromate concentration profiles for full-scale tests 4-6 at low dispersion (chamber section dispersion numbers calculated from a reference value $d_{1 \mathrm{~A}}=0.01$ at the reference flow rate $Q_{L}=13.2 \mathrm{MGD}$ ). 